\title{
Influence of environmental variables on macroinvertebrate community structure in Lianhuan Lake
}

\author{
Qianming Dou ${ }^{1}$, Xue Du ${ }^{1}$, Yanfeng Cong ${ }^{2}$, Le Wang ${ }^{1}$, Chen Zhao ${ }^{1}$, Dan Song ${ }^{1}$, Hui Liu ${ }^{1}$, \\ and Tangbin Huo ${ }^{1}$ \\ ${ }^{1}$ Heilongjiang River Fishery Research Institute of Chinese Academy of Fishery Sciences \\ ${ }^{2}$ Duerbert Mongolian Autonomous County Fisheries Terminal
}

September 25, 2021

\begin{abstract}
The characteristics of macroinvertebrate community structure can effectively reflect the health status of lake ecosystem and the quality of the lake ecological environment. It is of great significance to identify the limiting factors of macroinvertebrate community structure for the maintenance of lake ecosystem health. In this study, the community composition of macroinvertebrate assemblages and their relationships with environmental variables in 13 small lakes within Linhuan Lake was investigated. Self-organizing map, K-means clustering analysis, principal component analysis, pearson correlation analysis, and redundancy analysis were used to analyze the correlation and variability between macroinvertebrates community index and environmental factors. The results showed that the environmental variables ( $\mathrm{pH}$, total phosphorus, nitrate, water temperature, dissolved oxygen, conductivity, chemical oxygen demand, and ammonium) had a significant effect on the classification of macroinvertebrate community. Molluscs were significantly negatively correlated with $\mathrm{pH}$ and chlorophyll a, while annelids and aquatic insects were significantly positively correlated with chlorophyll a and dissolved oxygen. Species richness and Shannon's diversity of macroinvertebrates were significantly negatively correlated with total phosphorus while biomass of macroinvertebrates was significantly negatively correlated with $\mathrm{pH}$. High alkalinity characteristics and eutrophication of the lake have a serious impact on the macroinvertebrate community. Human interference and unreasonable industrial and surface runoff from agricultural farms destroy the ecological environment and affect the community structure of macroinvertebrate. Thus, the improvement of the macroinvertebrate's community structure should be carried out by improving the Lianhuan Lake watershed ecological environment and controlling watershed environmental pollution.
\end{abstract}

\section{Introduction}

Lake ecosystem is a typical spatial heterogeneous ecosystem formed by the interaction between lake biological community and the lake environment. The dynamic process can be shown by the four-dimensional changes of its biological and environmental elements(Protasov, 2008; Ward, 1989). If a lake is in a state of natural evolution and undisturbed by human beings possess a reasonable structure and perfect function, the lake is in a healthy state (Beck \& Hatch, 2009; Cooke, Welch, Peterson, \& Nichols, 2016). Because of the increase in human population, the speedy development of industrial production and domestic life, the human demand for water resources has been increasing in the recent decades. The problems such as the over-exploitation of water resources, the pollution of water ecological environment have become increasingly prominent. The structure and function of lake ecosystem had been seriously destroyed, and the health of lake ecosystems is gradually deteriorating (Likens, 2010; Tilzer \& Serruya, 2012).

As important groups of lake ecosystems, macroinvertebrates play an important role in lakes, altering the geochemical condition of sediments, promoting nutrient cycling and facilitating the transfer of energy among food webs (Cai, Gong, \& Qin, 2012; Odountan, de Bisthoven, Abou, \& Eggermont, 2019; Vaughn \& Hakenkamp, 2001). Macroinvertebrates are also commonly used as indicators of aquatic ecosystem integrity 
because of their wide range of sensitivity to pollution and relative longevity (Du et al., 2021; Richman \& Somers, 2010; Selvanayagam \& Abril, 2016).

The distribution of macroinvertebrate communities in aquatic systems is mainly affected by both natural factors and human activities (Z. Yu et al., 2020). The natural factors mainly include water temperature, water depth, dissolved oxygen, pH and spatial heterogeneity of habitats (Bazzanti, Della Bella, \& Grezzi, 2009; Free et al., 2009; Shostell \& Williams, 2007). Human activities such as agricultural production indirectly affect the community structure of macroinvertebrates by altering the nutrient level of within-lake water bodies (Wijesiri, Deilami, \& Goonetilleke, 2018).

Previous studies have showed that there is a strong correlation between macroinvertebrate community and environmental factors especially in streams and rivers (Kłonowska-Olejnik \& Skalski, 2014; S. Li et al., 2018; Zhang, Yang, Wan, Wang, \& Wang, 2021). However, little is known about macroinvertebrate assemblages and the environmental factors regulating their dynamics in lakes (Jiang et al., 2020; Song et al., 2007; White \& Irvine, 2003). Thus, analyzing the response relationship between macroinvertebrates and environmental factors has important guiding significance for improving lake ecological environment.

Lianhuan Lake which is located in Heilongjiang Province, is the largest alkaline lake in northern China. Lianhuan Lake was formed by tectonic slump and it consists of 18 small lakes around (Wen-hua, 2012). As an important lake in northern China, Lianhuan Lake plays an important role in climate regulation, replenishing groundwater, supporting biodiversity habitat and economic resource development (Lianjiang \& Shulan, 2011; Ma et al., 2018). However, in the recent years, with the agricultural reclaimed area in the lake catchment and tourism activities within the lake, the biodiversity loss and degradation of habitat and other problems have been more seriously (Jing, Shuying, Yanshan, Haifeng, \& Deqing, 2009; Sun, Zang, Xiao, \& Sun, 2010). At present, most of the studies which have been conducted in Lianhuan Lake are about assessment of heavy metals and nutrient elements in core sediments (Haifeng et al., 2010; Sun et al., 2010).

In this study, the community composition of macroinvertebrate assemblages and their relationships with environmental variables in 13 small lakes within Linhuan Lake was investigated. The 13 small lakes were chosen because they belong to the same watershed but differ in natural condition (e.g., lake morphology and environmental characteristics) which could result in different relationships between macroinvertebrate assemblages and environment factors. The aims of the study were as follows: (a) To determine the spatial and temporal patterns of the macroinvertebrate communities and the community groups, (b) To identify the indicator taxa's characterizing of each community group, and (c) To determine the important environmental variables shaping the community structure of macroinvertebrates in Lianhuan Lake. We expected that within-lake environmental variables would explain substantial amounts of variation in macroinvertebrates, so as to provide a scientific basis for protecting the health and biodiversity of the ecosystem in Lianhuan Lake.

\section{Material and Methods}

\section{Study area}

The study was conducted in Lianhuan Lake. Lianhuan Lake, formed by tectonic slump, consists of 18 small lakes around, is located in the most low-lying center of the Songnen Plain in eastern China (Fig. 1). The lake has a mean depth of $2.14 \mathrm{~m}$, a maximum depth of $4.6 \mathrm{~m}$, and a surface area of $580 \mathrm{~km}^{2}$ (G. Yu, Harrison, \& Xue, 2001). Lianhuan Lake become the first international waterfowl and hunting ground since 1985 in China. It lies in the cold temperate zone, characterized by semiarid climate. The average annual precipitation in the Lianhuan Lake catchment is $400 \mathrm{~mm}, 70 \%$ of which occurs in the summer (June to August). During March to May it is generally dry with a highest frequency of dust storms. Apart from direct precipitation, the lake also receives water from Wuyuer and Shuangyang rivers through the southern part. Rapid economic development around the lake has led to large quantities of wastewater, from agricultural, industrial, and domestic sources, being released into the lake. In this study, 13 small lakes around the Lianhuan Lake were considered. The 13 lakes are different in natural forms and area and they exhibit different characters such as nutrients levels, fisheries community, and human disturbance patterns. Interestingly, these lakes are 
connected to each other. Among the 13 small lakes covered in this study, Habuta lake is geographically located far from the other lakes. Delong Lake, Yangcaohao Lake and Beiqin Lake are located in the upper reaches of Lianhuan lake. Durbote county is located to the east of these lakes (R. Wang et al., 2019).

\section{Macroinvertebrate sampling}

Sampling took place in spring (June), summer (August), and autumn (October) of 2021 at the at each site (Fig. 1). At each site, quantitative Petersen grab samples $\left(0.025 \mathrm{~m}^{2}\right)$ were collected in replicates and processed through a $300 \mu \mathrm{m}$ mesh size sieve. Petersen grab and the mesh size sieve were visually inspected to ensure macroinvertebrates adhering to the grab and sieve were transferred to the composite sample. All materials were placed into a plastic jar and preserved in $80 \%$ alcohol. In the laboratory, all organisms in the samples were counted, weighed to the nearest $0.1 \mathrm{~g}$ and identified to genus or to the lowest taxonomic level possible. Species abundance for each sampling site was calculated as a density (individuals $\mathrm{m}^{-2}$ ) and biomass $\left(\mathrm{gm}^{-2}\right)$ was calculated by adding the biomass of all species. The identification and classification of the macroinvertebrates was done according to (Dudgeon, 1999; Morse, Yang, \& Tian, 1994; H. Wang, 2002)

\section{Environmental variables}

The Lake surface area was calculated using ArcGIS (ver. 10.7). At each sampling site, water temperature $(\mathrm{WT}$,$) , conductivity (\mathrm{COND}, \mu \mathrm{S} / \mathrm{cm}), \mathrm{pH}$, and dissolved oxygen $(\mathrm{DO}, \mathrm{mg} / \mathrm{L})$ were measured in the field using a portable YSI Professional Plus instrument (made in the USA). Water depth (WD, m) was measured with a Speedtech handheld depth finder (made in the USA). Water was collected directly into 5-L polypropylene bottles at a depth of $0.5 \mathrm{~m}$ to quantify water chemistry factors. The water chemical including total phosphorus (TP, mg/L), total nitrogen (TN, mg/L), ammonium $\left(\mathrm{NH}_{4}-\mathrm{N}, \mathrm{mg} / \mathrm{L}\right)$, nitrate $\left(\mathrm{NO}_{3}-\mathrm{N}, \mathrm{mg} / \mathrm{L}\right)$, nitrite $\left(\mathrm{NO}_{2}-\mathrm{N}, \mathrm{mg} / \mathrm{L}\right)$, chemical oxygen demand $\left(\mathrm{COD}_{\mathrm{Mn}}, \mathrm{mg} / \mathrm{L}\right)$, Chlorophyll $a$ concentration (Chla, $\left.\mathrm{mg} / \mathrm{L}\right)$, and Suspended substance (SS, mg/L), were measured in the laboratory based on standard methods (Federation \& Association, 2005). Chlorophyll $a$ concentration (Chla, $\mathrm{mg} / \mathrm{L}$ ) was determined according to the protocols for standard observation and measurement in aquatic ecosystems by filtering $100 \mathrm{~mL}$ of the sampled water through GF/C whatman filter. Pigments extraction was done in $90 \%$ aqueous solution of acetone and Chla concentrations were measured spectrometrically

\section{Classification of macroinvertebrate communities using Self-Organising Map}

In order to analyze the classification macroinvertebrate communities, Self-organizing map (SOM) was applied for classifying sampling points according to the species' abundance. SOM is an effective method for cluster analysis, which has a high explanatory ability in the study of ecological population(Giraudel \& Lek, 2001). SOM consists of two layers of neurons, namely the input layer and the output layer connected by connection intensities (weights). Input layers acquire information from a data matrix, and output layers visualize the computational results (Song et al., 2007). In this study, the input layer was composed of species abundance and 74 sample points. The number of neurons in the output layer was determined in advance according as 5 $\times \sqrt{\text { numberofsamplepoints }}[?] 43$ (Park, Cereghino, Compin, \& Lek, 2003), and according to the minimum quantization error and the minimum topographic error (see Appendix S1 in Table S1). The optimal number of neurons in the output layer was determined to be 49 (Kohonen, 2001). Since SOM output layer has no distinct classification boundaries. $K$-means clustering analysis was performed on the SOM output layer neurons and classified the neurons into different groups. The Simple structure index (SSI) which is the value indicating the relative importance of each species in determining the distribution patterns of the samples in the SOM was then used to determine the optimal number of groups (Park et al., 2006). Therefore, the larger the values of SSI the higher the clustering quality (Dimitriadou, Dolničar, \& Weingessel, 2002; Park et al., 2006).

Indicator species is a species closely related to environmental changes, used to measure the specificity and fidelity of a species to a certain environmental state (McGeoch, Van Rensburg, \& Botes, 2002). Indicator values (IndVal) of all species in each group were calculated to determine the indicator species in each group. A 1000 permutations were performed to access the significance $(P<0.05)$ of the IndVal observed for each species (Arimoro \& Keke, 2021). The calculation formula of IndVal was done as follows (Dufrêne \& Legendre, 
1997):

\section{$A_{i j}=$ Nindividuals $_{i j} /$ Nindividuals $_{i}$}

\section{$B_{i j}=$ Nsites $_{i j} /$ Nsites $_{j}$}

\section{$\operatorname{IndVal}_{i j}=A_{i j} \times B_{i j} \times 100$}

Where IndVal is the Indicator Value of species $i$ in site cluster $j, A_{i j}$, is a measure of specificity, Nindividuals $i j$ is the mean number of individuals of species $i$ across sites of group $j$, while Nindividuals $_{i}$. is the sum of the mean numbers of individuals of species $i$ over all groups. $B$, is a measure of fidelity, Nsites ${ }_{i j}$ is the number of sites in cluster $j$ where species $i$ is present, while Nsites. $j$ is the total number of sites in that cluster. $B_{i j}$ is maximum when species $i$ is present in all objects of cluster $j$. Indval greater than $50 \%$ were regarded as criteria to determine indicator species.

Five index of macroinvertebrate community namely species richness, abundance, biomass, Shannon's diversity, and Pielou's evenness were also determined in this study.

Statistical analysis

Prior to analysis, the macroinvertebrate abundance data was log-transformed Hellinger-transformed for SOM and Redundancy analysis (RDA), respectively. With exception of $\mathrm{pH}$, all the environmental variables were log-transformed to satisfy the normality and variance assumption before doing PCA and RDA analysis. To analyze whether the classification of macroinvertebrate community was affected by environmental variables, Principal component analyses (PCA) was conducted to test the variation of environmental variables in each group, and the correlation between environmental variables was evaluated. Kruskal-Wallis test was performed to determine the important variables affecting the classification of macroinvertebrate community. The relationship between environmental variables and macroinvertebrate species composition were evaluated through RDA using rda function in the vegan package (Oksanen et al., 2013) of the R (version 3.6.3) statistical software (Team, 2019). Variance inflation factors (VIF) was used to test multicollinearity among environmental variables. Stepwise forward selection (Monte Carlo test with 999 permutations) was used to determine the environmental variables significantly correlated with the macroinvertebrate species. The statistical significance of species-environment correlations for the ordination axes were also determined based on 999 Monte Carlo permutation tests, and the eigenvalues of the first 2 axes were used to measure their importance (Ter Braak \& Verdonschot, 1995). Spearman correlation analysis was used to evaluate the response of these community index to environmental variables. The two-tailed Student's $t$ test (T-test) was used to test for significance $(P<0.05)$, while $P$-values were adjusted using the multiple comparisons test (Benjamini \& Hochberg, 1995). SOM was conducted using the ANN Toolbox on Matlab software, R2010b (The MathWorks Inc., Natick, MA, USA). Shannon's diversity and Pielou's evenness were calculated in Primer (ver. E-v5) (Clarke \& Gorley, 2001). K -means clustering analysis were performed in the vegan package (Oksanen et al., 2013) of the $\mathrm{R}$ (version 3.6.3) statistical software (Team, 2019). IndVal, PCA, 
ANOVA, and spearman correlation analysis were performed in the labdsv package (Roberts \& Roberts, 2016), ade4 package (Dray \& Siberchicot, 2020), agricolae package (de Mendiburu \& de Mendiburu, 2019), and psych package (Revelle \& Revelle, 2015) of R statistical software.

\section{Results}

A total of 44 macroinvertebrate taxa were collected and identified from all the sampling points during the study period which included 23 aquatic insects, 10 gastropods, 4 bivalves, 4 oligochaetes, 2 leeches and 1 crustacean (see Appendix S1in Table S2). Simple structure index (SSI) showed that when the neurons in the SOM output layer were divided into five groups, the clustering quality was the highest (Fig. 2a). SOM revealed both spatial and seasonal variation in the classification of macroinvertebrate community (Fig. 2b). Most of the sampling points in the autumn were grouped in Group I in the left-top area of the map. Group $\mathrm{V}$ located at the right-bottom area of the map mainly included the upper reaches of Lianhuan lake measured in spring and summer. All seasonal sampling points of Habuta Lake, which was farther away from other lakes, were grouped in Group II in the left-bottom area of the map. Most seasonal sampling points in the south-central part of Lianhuan Lake were grouped in Group III in the top area of the map. Most seasonal sampling points in the eastern part of Lianhuan Lake, which was closer to Durbote County, were grouped in Group IV in the right-top area of the map.

Variations of environmental variables, including WT, COND, pH, DO, TP, $\mathrm{NH}_{4}-\mathrm{N}, \mathrm{NO}_{3}-\mathrm{N}$, and $\mathrm{COD}_{\mathrm{Mn}}$ in water in all seasons across the Lianhuan Lake are summarized in Fig. 4. All the environmental variables presented were statistically significant different among the groups. Group I which principally encompasses samples that were taken in autumn in the top-left area of the Lianhuan Lake, was characterized by lower values of $\mathrm{WT}, \mathrm{NH}_{4}-\mathrm{N}$ and $\mathrm{COD}_{\mathrm{Mn}}$ and high values of $\mathrm{DO}, \mathrm{COND}, \mathrm{TP}$, and $\mathrm{NO}_{3}-\mathrm{N}$. Group II which include sampling points located in Habuta lake on the bottom-left area of the Lianhuan Lake was characterized by high WT, $\mathrm{pH}$ and $\mathrm{COD}_{\mathrm{Mn}}$ values. High $\mathrm{pH}$ values and relatively low $\mathrm{COD}_{\mathrm{Mn}}$ characterized sampling points grouped in Group III located at the top area (South) of the map. Group IV which encompasses samples that were taken in spring and autumn at the bottom-right area of the map and included the upper reaches of Lianhuan lake was characterized by high values of $\mathrm{WT}, \mathrm{pH}$, and $\mathrm{NH}_{4}-\mathrm{N}$ and low values of $\mathrm{DO}$ and $\mathrm{NO}_{3}-\mathrm{N}$. Sampling sites which were located closer to Durbote County grouped in Group V were characterized by high WT, DO and $\mathrm{NH}_{4}-\mathrm{N}$.

According to IndVal [?]50\% criterion, a total of 29 macroinvertebrates were found to be useful as indicator species for different groups (Table 1). However, 13 species with indicator values lower than $50 \%$ (31.89$48.98 \%$ ) was also considered to be significant and important for particular groups. There were significant variations in the indicator species and the number of indicator species among the five groups. Group II had the most diverse indicator species, including one crustacean, three annelids, four molluscs, and five aquatic insects. Group III had only two indicator species, both of which belong to the Chironomidae. The indicator species of groups I and IV were dominated by Chironomidae and Mollusca. Group V indicator species were mainly characterized by Mollusca. It is worth noting that many indicator species such as Anatopynia sp and G. pervia, G. albus were distributed in two or more groups (see Appendix S1 in Table S2), implying that the differences in the indicator species between groups mainly resulted from differences in the abundance of the taxa for each group.

The PCA using 13 environmental variables explained $44.9 \%$ of the data variability in the first two axes (axis $1=23.8 \%$ of the total variance with eigenvalues of 3.10 and axis $2=21.1 \%$ of the total variance with eigenvalues of 2.74). In axis 1 , the most important variables which were positive correlated were $\mathrm{NO}_{2}-\mathrm{N}, \mathrm{TP}$, $\mathrm{pH}$, SS, Chla, and DO while TN and WD were negatively correlated. Axis 1 fundamentally distinguished 2 groups: Group I and Group V. With respect to axis 2, the most important environmental variables which were positive correlated are $\mathrm{TP}, \mathrm{WT}, \mathrm{NH}_{4}-\mathrm{N}$, and $\mathrm{COD}_{\mathrm{Mn}}$. Total phosphorus (TP), $\mathrm{NO}_{3}-\mathrm{N}$ and COND were negatively correlated with axis 2 . Kruskal-Wallis test results indicated that $\mathrm{pH}, \mathrm{TP}, \mathrm{NO}_{3}-\mathrm{N}, \mathrm{WT}, \mathrm{DO}$, $\mathrm{COND}, \mathrm{COD}_{\mathrm{Mn}}$, and $\mathrm{NH}_{4}-\mathrm{N}$ had a significant effect on the classification of macroinvertebrate community (Fig. 4). 
The RDA ordination of the macroinvertebrate composition with respect to environmental variables are presented in Fig. 5. Using the function ordistep from vegan package to conduct forward selection and screening of the environmental variables yielded 4 variables that were significant to the model. These variables were WT, $\mathrm{pH}, \mathrm{DO}$ and Chla (Fig. 5). These 4 variables accounted for $77 \%$ of the total variance in the macroinvertebrate species composition. The first RDA axis which explained $45.3 \%$ of the total variability was positively correlated to $\mathrm{WT}$ while the second axis which explained $32.4 \%$ variability was positive correlated with $\mathrm{pH}$. Among the strongest species-environment associations, we found that molluscs, such as $G$. albus, $R$. pereger, and $S$. glabra were significantly positively correlated with WT and negatively to $\mathrm{pH}$ and Chla. Annelids, such as B. sowerkyi and Herpobdella sp, were significantly positively correlated with Chla and DO, and negatively to pH. Aquatic insects, such as Chaoborus sp,Ephemera sp, and Anatopynia sp were were significantly positively correlated with Chla and DO,and negatively to WT.

From the Spearman correlation analysis (Table 2), the community index of macroinvertebrates was significantly affected by environmental variables. Macroinvertebrate abundance was most affected by environmental variables and was significantly negatively correlated with DO $(R=-0.40, P=0.01), \mathrm{NO}_{2}-\mathrm{N}(R$ $=-0.33, P=0.04)$ and Chla $(R=-0.32, P=0.04)$. Both species richness and Shannon's diversity were significantly negatively correlated with TP $(R=-0.35, P=0.04$ and $R=-0.34, P=0.04)$. The biomass of macroinvertebrates was significantly negatively correlated with $\mathrm{pH}(R=-0.39, P=0.01)$.

\section{Discussion}

The understanding on ecological status of lakes helps determine the ecosystem services provided by them (Grizzetti, Lanzanova, Liquete, Reynaud, \& Cardoso, 2016). Therefore, it is important to assess them. Ecological status and water quality is affected by a complex interaction of environmental variables. Understanding the relative effects of these environmental variables is a necessary step in determining the activities required for lake management. The macroinvertebrates community is an ideal indicator to assess impacts as they respond to a wide variety of physical, chemical and biological factors (Rai, Shah, Shah, \& Milner, 2019). This study aimed to investigate the response of macroinvertebrate community structure to environmental variables of Lianhuan Lake.

The community of macroinvertebrate were used to classify the spatial patterns of the lake for the purpose of biogeographical division. Based on the species composition, the SOM grouped the sampling sites into four groups. This classification could imply that spatial variation correlated with the macroinvertebrate communities on a small-scale. Kruskal-Wallis test indicated that the environmental variables differed significantly among the 5 groups. Groups with similar macroinvertebrates communities were placed close to each other in the SOM. Groups I and V were placed furthest in the SOM, and this was further depicted in the final result of principal component analyses (PCA).

Group I which principally encompasses samples that were taken in autumn in the top-left area of the Lianhuan Lake, was characterized by lower WT and high values of DO, COND, TP, and $\mathrm{NO}_{3}-\mathrm{N}$. The high DO, COND, TP, and $\mathrm{NO}_{3}-\mathrm{N}$, could be attributed to the fact these sampling sites were located near to the river mouth which discharges water into the lakes from the surrounding agricultural farms (Fu-hua \& Shuying, 2010; Xiao et al., 2014). The indicator species for Group I were Chironomidae and C. fluminea which are more tolerant to eutrophication conditions (Zhijun, Ping, Huijuan, \& Shida, 2001). C. fluminea has been documented to tolerate low temperature (Gerard et al., 2009; Min, 2008). Group II included sampling point in was Habuta lake was characterized by high $\mathrm{COD}_{\mathrm{Mn}}, \mathrm{TP}, \mathrm{NH}_{4}-\mathrm{N}$ and $\mathrm{NO}_{3}-\mathrm{N}$. Interestingly, annelids such as B. sowerkyi and Herpobdella sp related to lake excess nutrients (Cai et al., 2017; Du et al., 2021) were remarkable high in Group II. This implies that even though Habuta Lake is located far away from the other lakes, their source of the water is the same as the other lakes. The status of the Habuta Lake could be at the stage of degradation due to eutrophication.

A significant variability of environmental variables was recorded in Group IV which encompasses sampling points from the eastern part of Lianhua Lake. $\mathrm{COD}_{\mathrm{Mn}}$, TP, and $\mathrm{NH}_{4}-\mathrm{N}$ were markedly high, while DO was notably low in Group IV likely because of the dominant human activities such as crop farming on the 
eastern part of Lake (Xiao et al., 2014). Increased agriculture and urban land uses can significantly change lake physicochemical characteristics (Huang et al., 2014; Johnson, Furse, Hering, \& Sandin, 2007; Mathur, Agarwal, \& Nag, 2007). Increases in urban and agricultural land uses have been proven to increase nutrients and change in macroinvertebrate indicator species (Johnson, Wiederholm, \& Rosenberg, 1993; Kubosova, Brabec, Jarkovsky, \& Syrovatka, 2010; S. Yu, Xu, Wu, \& Zuo, 2016). G. pervia, Clinotarypus sp and Tanypus sp indicators species were grouped in Group IV possible due to the fact that they are tolerant to high levels of pollution (J. Wang, 2003). These species respond to organic pollution by increase in abundance. Being grouped in Group IV is an attestation to this fact. They can live in extremely polluted waters with very low oxygen levels (Uwadiae, 2016).

This study also revealed that Delong Lake, Yangcaohao Lake and Beiqin Lake grouped in Group V were characterized by good water quality. This is despite the fact that these three lakes were located in the upper reaches of Lianhuan lake and sampled during summer when large amount of water are discharged by through surface runoff. This clearly shows that there is spatial variation in terms of water quality. The fact that many indicator species were grouped in Group V also implies that the conditions in Group V allowed many organisms to thrive.

Macroinvertebrates are important part of the lake ecosystem and the characteristics of community structure were related to lake environmental variables. This study revealed that that $\mathrm{pH}, \mathrm{TP}, \mathrm{NO}_{3}-\mathrm{N}, \mathrm{WT}, \mathrm{DO}, \mathrm{COND}$, $\mathrm{COD}_{\mathrm{Mn}}$, and $\mathrm{NH}_{4}-\mathrm{N}$ had a significant effect on the classification of macroinvertebrate community (Fig. 4). $\mathrm{pH}$ has been shown to play a role in influencing the composition and abundance of macroinvertebrate communities. Study by Feldman and Connor (1992) indicate that acid water has reduced macroinvertebrate abundance, biomass, and diversity. Moreover, the tolerance studies have revealed that the tolerance to $\mathrm{pH}$ varies between macroinvertebrates species (Ormerod et al., 1987). Based on the RDA and spearman correlation analysis, the biomass of macroinvertebrates mainly mollusks was significantly negatively correlated with $\mathrm{pH}$ in this lake. This could be attributed by the high $\mathrm{pH}$ values in the range of 8 to 10 which is experienced in the lake all year round (Jing et al., 2009). It has been documented that an extreme pH environment can directly produce toxic effects on Mollusca, and under certain conditions, it can endanger the normal survival of organisms (Wu et al., 2018). Peiffer, Beierkuhnlein, Sandhage-Hofmann, Kaupenjohann, and Bär (1997) also noted that decrease of $\mathrm{pH}$ will not only directly affect the birth rate of benthic invertebrates, reduce their biodiversity, but also cause benthic invertebrate poisoning by triggering the release of heavy metals. This could be another possible explanation for the negative influence of $\mathrm{pH}$ to macroinvertebrates because study by Jing et al. (2009) in the Lianhuan Lake revealed that the acidity and alkalinity of the lake has changed with the differential enrichment of heavy metals caused by the discharge of industrial sewage.

Water temperature (WT) affects the physiological processes of organisms, so temperature dynamics may change life cycle patterns and trophic interactions (F. Li, Cai, Jiang, \& Qu, 2012). This may alter the community composition and biodiversity. According to the RDA results, most of the macroinvertebrates were significantly positively correlated with WT which is in agreement with other studies (Buss, Baptista, Nessimian, \& Egler, 2004). Water temperature (WT) is an important factor for embryonic development, larval growth, emergence, metabolism and survivorship of macroinvertebrate (Haidekker \& Hering, 2008). The fact that many indicator species were recorded in Group V further shows that WT is an important factor because these sites were sampled during summer and spring.

Nutrients are essential for maintaining an ecosystem's structure and function. However, excessive nutrients can also reduce water quality causing problems and can deplete dissolved oxygen, leading to death of aquatic organisms (Ouyang, Qian, Becker, \& Chen, 2018). On average, macroinvertebrates species richness and abundance in this study exhibits a subsidy-stress relationship with nutrients mainly TP and $\mathrm{NO}_{2}-\mathrm{N}$. This result is consistent with the conclusion that a high level of nutrient concentrations negatively affects benthic invertebrate species richness and abundance, a conclusion also found in manipulative experiments and observational studies (Dodson, Arnott, \& Cottingham, 2000; L. Wang, Robertson, \& Garrison, 2007). When nutrients are excessive in a lakes as observed in Group IV, the diminished water quality and the depleted oxygen caused by decomposition of algal bloom biomass will likely reduce species richness (L. Wang et al., 
2007), leading to a negative association between nutrients and species richness. The high nutrients concentration recorded in this lake could be attributed to the use of phosphatic fertilizers to increase agricultural production.

\section{Conclusion}

In this study, the analysis of macroinvertebrate assemblage identifies gradient of macroinvertebrate diversity in Lianhuan Lake. It also captured the spatiotemporal variation in macroinvertebrate community structure and indicator species in the Lake. The SOM analysis of the macroinvertebrate communities revealed that eutrophication causes serious impacts to the macroinvertebrate communities. The differences in the community structure and environmental variables between Groups I and V is remarkable and the indicator species are reflecting the environmental characteristics of each group of communities. The high alkalinity characteristics and eutrophication of the lake may have a serious impact on the macroinvertebrate community. This is clearly shown by the significant negatively correlation between the biomass of macroinvertebrates and $\mathrm{pH}$, as well as the negative correlation between species richness and Shannon's diversity with TP. High-intensity human interference and unreasonable industrial and surface runoff from agricultural farms destroy the ecological environment and affect the community structure of macroinvertebrate. Thus, the improvement of the macroinvertebrate's community structure should be carried out by improving the Lianhuan Lake watershed ecological environment and controlling watershed environmental pollution (Non-point source pollution).

\section{References}

Arimoro, F. O., \& Keke, U. N. (2021). Stream biodiversity and monitoring in North Central, Nigeria: the use of macroinvertebrate indicator species as surrogates. Environmental Science and Pollution Research, 1-10.

Bazzanti, M., Della Bella, V., \& Grezzi, F. (2009). Functional characteristics of macroinvertebrate communities in Mediterranean ponds (Central Italy): influence of water permanence and mesohabitat type. Paper presented at the Annales de Limnologie-International Journal of Limnology.

Beck, M. W., \& Hatch, L. K. (2009). A review of research on the development of lake indices of biotic integrity. Environmental Reviews, 17(NA), 21-44.

Benjamini, Y., \& Hochberg, Y. (1995). Controlling the false discovery rate: a practical and powerful approach to multiple testing. Journal of the Royal statistical society: series B (Methodological), 57(1), 289-300.

Buss, D. F., Baptista, D. F., Nessimian, J. L., \& Egler, M. (2004). Substrate specificity, environmental degradation and disturbance structuring macroinvertebrate assemblages in neotropical streams. Hydrobiologia, 518(1), 179-188.

Cai, Y., Gong, Z., \& Qin, B. (2012). Benthic macroinvertebrate community structure in Lake Taihu, China: effects of trophic status, wind-induced disturbance and habitat complexity. Journal of Great Lakes Research, $38(1), 39-48$.

Cai, Y., Xu, H., Vilmi, A., Tolonen, K. T., Tang, X., Qin, B., . . Heino, J. (2017). Relative roles of spatial processes, natural factors and anthropogenic stressors in structuring a lake macroinvertebrate metacommunity. Science of the Total Environment, 601, 1702-1711.

Clarke, K. R., \& Gorley, R. N. (2001). Primer V5 (Plymouth routines in multivariate ecological research): user manual/tutorial: Primer-e.

Cooke, G. D., Welch, E. B., Peterson, S., \& Nichols, S. A. (2016). Restoration and management of lakes and reservoirs: CRC press.

de Mendiburu, F., \& de Mendiburu, M. F. (2019). Package 'agricolae'. R Package, Version, 1-2.

Dimitriadou, E., Dolničar, S., \& Weingessel, A. (2002). An examination of indexes for determining the number of clusters in binary data sets. Psychometrika, 67(1), 137-159. 
Dodson, S. I., Arnott, S. E., \& Cottingham, K. L. (2000). The relationship in lake communities between primary productivity and species richness. Ecology, 81(10), 2662-2679.

Dray, S., \& Siberchicot, M. A. (2020). Package 'ade4'. Université de Lyon, France.

Du, X., Song, D., Ming, K., Jin, X., Wang, H., Wang, L., . . Huo, T. (2021). Response of macroinvertebrate communities to land use and water quality in Wudalianchi Lake. Ecology and evolution, 11(3), 1368-1377.

Dudgeon, D. (1999). Tropical Asian streams: zoobenthos, ecology and conservation (Vol. 1): Hong Kong University Press.

Dufrêne, M., \& Legendre, P. (1997). Species assemblages and indicator species: the need for a flexible asymmetrical approach. Ecological monographs, 67(3), 345-366.

Federation, W. E., \& Association, A. (2005). Standard methods for the examination of water and wastewater. American Public Health Association (APHA): Washington, DC, USA.

Feldman, R. S., \& Connor, E. F. (1992). The relationship between pH and community structure of invertebrates in streams of the Shenandoah National Park, Virginia, USA. Freshwater Biology, 27(2), 261-276.

Free, G., Solimini, A. G., Rossaro, B., Marziali, L., Giacchini, R., Paracchini, B., . . Fresner, R. (2009). Modelling lake macroinvertebrate species in the shallow sublittoral: relative roles of habitat, lake morphology, aquatic chemistry and sediment composition. Hydrobiologia, 633(1), 123-136.

Fu-hua, X., \& Shu-ying, Z. (2010). Characteristics of heavy meatals and nutrients of core Huoshaohei sediments in Lianhuan lake. Paper presented at the 2010 International Conference on Mechanic Automation and Control Engineering.

Gerard, C., Poullain, V., Lance, E., Acou, A., Brient, L., \& Carpentier, A. (2009). Influence of toxic cyanobacteria on community structure and microcystin accumulation of freshwater molluscs. Environmental pollution, 157(2), 609-617.

Giraudel, J., \& Lek, S. (2001). A comparison of self-organizing map algorithm and some conventional statistical methods for ecological community ordination. Ecological Modelling, 146(1-3), 329-339.

Grizzetti, B., Lanzanova, D., Liquete, C., Reynaud, A., \& Cardoso, A. (2016). Assessing water ecosystem services for water resource management. Environmental Science \& Policy, 61, 194-203.

Haidekker, A., \& Hering, D. (2008). Relationship between benthic insects (Ephemeroptera, Plecoptera, Coleoptera, Trichoptera) and temperature in small and medium-sized streams in Germany: a multivariate study. Aquatic Ecology, 42(3), 463-481.

Haifeng, X., Shuying, Z., Zhaohong, M., Jia, Z., Jing, L., Xiayun, X., \& Enfeng, L. (2010). Analysis on Evolution of Total Nitrogen and Organic Matter in Sediment of Yamenxi Lake of Lianhuan Lake [J]. Natural Science Journal of Harbin Normal University, 5.

Huang, C., Wang, X., Yang, H., Li, Y., Wang, Y., Chen, X., \& Xu, L. (2014). Satellite data regarding the eutrophication response to human activities in the plateau lake Dianchi in China from 1974 to 2009. Science of the Total Environment, 485, 1-11.

Jiang, W., Pan, B., Chen, J., Jiang, X., Shen, H., \& Zhu, T. (2020). Macroinvertebrate Communities in a Lake of an Inter-Basin Water Transfer Project and Its Implications for Sustainable Management. Water, 12(7), 1900.

Jing, L., Shuying, Z., Yanshan, S., Haifeng, X., \& Deqing, Z. (2009). Speciation Analysis of Heavy Metals in Sediment from Amuta lake of Lianhuan Lake [J]. Environmental Science and Management, 1.

Johnson, R. K., Furse, M. T., Hering, D., \& Sandin, L. (2007). Ecological relationships between stream communities and spatial scale: implications for designing catchment-level monitoring programmes. Freshwater Biology, 52(5), 939-958. 
Johnson, R. K., Wiederholm, T., \& Rosenberg, D. M. (1993). Freshwater biomonitoring using individual organisms, populations, and species assemblages of benthic macroinvertebrates. Freshwater biomonitoring and benthic macroinvertebrates, 40, 158 .

Kłonowska-Olejnik, M., \& Skalski, T. (2014). The effect of environmental factors on the mayfly communities of headwater streams in the Pieniny Mountains (West Carpathians). Biologia, 69(4), 498-507.

Kohonen, T. (2001). Self-organizing maps, ser. Information Sciences. Berlin: Springer, 30.

Kubosova, K., Brabec, K., Jarkovsky, J., \& Syrovatka, V. (2010). Selection of indicative taxa for river habitats: a case study on benthic macroinvertebrates using indicator species analysis and the random forest methods. Hydrobiologia, 651(1), 101-114.

Li, F., Cai, Q., Jiang, W., \& Qu, X. (2012). Macroinvertebrate relationships with water temperature and water flow in subtropical monsoon streams of Central China: implications for climate change. Fundamental and Applied Limnology-Archiv furHydrobiologie, 180(3), 221.

Li, S., Yang, W., Wang, L., Chen, K., Xu, S., \& Wang, B. (2018). Influences of environmental factors on macroinvertebrate assemblages: differences between mountain and lowland ecoregions, Wei River, China. Environmental monitoring and assessment, 190(3), 1-13.

Lianjiang, W. L. Z. H. S., \& Shulan, Z. L. H. D. L. (2011). Evaluation and Research of Water Quality Environment in Lianhuan Lake Hunting Ground. Chemical Industry Times, 08.

Likens, G. E. (2010). Lake ecosystem ecology: a global perspective: Academic Press.

Ma, Y., Li, J., Wu, J., Kong, Z., Feinstein, L. M., Ding, X., . . . Wu, L. (2018). Bacterial and fungal community composition and functional activity associated with lake wetland water level gradients. Scientific reports, $8(1), 1-12$.

Mathur, P., Agarwal, S., \& Nag, M. (2007). Assessment of physicochemical characteristics and suggested restoration measures for Pushkar Lake, Ajmer Rajasthan (India). Paper presented at the Proceedings of Taa2017: The 12th World Lake Conference.

McGeoch, M. A., Van Rensburg, B. J., \& Botes, A. (2002). The verification and application of bioindicators: a case study of dung beetles in a savanna ecosystem. Journal of applied ecology, 39(4), 661-672.

Min, L. (2008). Ecological Characteristics of Corbicula fluminea and Its Effect on the Heavy Metals Accumulation. Journal of Anhui Agricultural Sciences, 36(1), 221.

Morse, J. C., Yang, L., \& Tian, L. (1994). Aquatic insects of China useful for monitoring water quality: Hohai University Press.

Odountan, O. H., de Bisthoven, L. J., Abou, Y., \& Eggermont, H. (2019). Biomonitoring of lakes using macroinvertebrates: recommended indices and metrics for use in West Africa and developing countries. Hydrobiologia, 826(1), 1-23.

Oksanen, J., Blanchet, F. G., Kindt, R., Legendre, P., Minchin, P. R., O’hara, R., . . . Wagner, H. (2013). Package 'vegan'. Community ecology package, version, 2(9), 1-295.

Ormerod, S., Boole, P., McCahon, C., Weatherley, N., Pascoe, D., \& Edwards, R. (1987). Short-term experimental acidification of a Welsh stream: comparing the biological effects of hydrogen ions and aluminium. Freshwater Biology, 17(2), 341-356.

Ouyang, Z., Qian, S. S., Becker, R., \& Chen, J. (2018). The effects of nutrients on stream invertebrates: a regional estimation by generalized propensity score. Ecological processes, 7(1), 1-13.

Park, Y.-S., Céréghino, R., Compin, A., \& Lek, S. (2003). Applications of artificial neural networks for patterning and predicting aquatic insect species richness in running waters. Ecological Modelling, 160(3), 265-280. 
Park, Y.-S., Tison, J., Lek, S., Giraudel, J.-L., Coste, M., \& Delmas, F. (2006). Application of a self-organizing map to select representative species in multivariate analysis: a case study determining diatom distribution patterns across France. Ecological Informatics, 1(3), 247-257.

Peiffer, S., Beierkuhnlein, C., Sandhage-Hofmann, A., Kaupenjohann, M., \& Bär, S. (1997). Impact of high aluminium loading on a small catchment area (thuringia slate mining area) - geochemical transformations and hydrological transport. Water, Air, and Soil Pollution, 94(3), 401-416.

Protasov, A. A. (2008). River and lake continua: an attempt at analysis and synthesis. Inland Water Biology, $1(2), 105-113$.

Rai, A., Shah, D., Shah, R., \& Milner, C. (2019). Influence of environmental parameters on benthic macroinvertebrate assemblages in the headwaters of Bagmati river, Kathmandu valley, Nepal. Banko Janakari, $29(1), 53-61$.

Revelle, W., \& Revelle, M. W. (2015). Package 'psych'. The comprehensive R archive network, 337, 338.

Richman, L. A., \& Somers, K. (2010). Monitoring metal and persistent organic contaminant trends through time using quagga mussels (Dreissena bugensis) collected from the Niagara River. Journal of Great Lakes Research, 36(1), 28-36.

Roberts, D. W., \& Roberts, M. D. W. (2016). Package 'labdsv'. Ordination and Multivariate, 775.

Selvanayagam, M., \& Abril, R. (2016). Use of benthic macro invertebrates as a biological indicator in assessing water quality of river Puyo, Puyo, Pastaza, Ecuador. American Journal of Life Sciences, 4(1), 1-12.

Shostell, J. M., \& Williams, B. S. (2007). Habitat complexity as a determinate of benthic macroinvertebrate community structure in cypress tree reservoirs. Hydrobiologia, 575(1), 389-399.

Song, M.-Y., Hwang, H.-J., Kwak, I.-S., Ji, C. W., Oh, Y.-N., Youn, B. J., \& Chon, T.-S. (2007). Selforganizing mapping of benthic macroinvertebrate communities implemented to community assessment and water quality evaluation. Ecological Modelling, 203(1-2), 18-25.

Sun, L., Zang, S., Xiao, H., \& Sun, H. (2010). Sedimentary record of heavy metals and nutrient elements in core sediments from Talahong sub-lake in the Lianhuan lake. Geogr Geo-Information Sci, 26(4), 99-103.

Team, R. C. (2019). 2020. R: A Language and Environment for Statistical Computing. R Foundation for Statistical Computing, Vienna, Austria: Available at: https://www . R-project. org/.[Google Scholar].

Ter Braak, C. J., \& Verdonschot, P. F. (1995). Canonical correspondence analysis and related multivariate methods in aquatic ecology. Aquatic sciences, 57(3), 255-289.

Tilzer, M. M., \& Serruya, C. (2012). Large lakes: ecological structure and function: Springer Science \& Business Media.

Uwadiae, R. (2016). Benthic macroinvertebrate community and chlorophyll a (chl-a) concentration in sediment of three polluted sites in the Lagos Lagoon, Nigeria. Journal of Applied Sciences and Environmental Management, 20(4), 1137-1145.

Vaughn, C. C., \& Hakenkamp, C. C. (2001). The functional role of burrowing bivalves in freshwater ecosystems. Freshwater Biology, 46(11), 1431-1446.

Wang, H. (2002). Studies on taxonomy, distribution and ecology of microdrile oligochaetes of China, with descriptions of two new species from the vicinity of the Great Wall Station of China, Antarctica. Higher Education (HEP), Beijing.

Wang, J. (2003). Tolerance values of benthic macroinvertebrates and bioassessment of water quality in the Lushan Nature Reserve. Chinese Journal of Applied and Environmental Biology, 9(3), 279-284. 
Wang, L., Robertson, D. M., \& Garrison, P. J. (2007). Linkages between nutrients and assemblages of macroinvertebrates and fish in wadeable streams: implication to nutrient criteria development. Environmental management, 39(2), 194-212.

Wang, R., Dearing, J. A., Doncaster, C. P., Yang, X., Zhang, E., Langdon, P. G., . . Xu, M. (2019). Network parameters quantify loss of assemblage structure in human-impacted lake ecosystems. Global change biology, 25(11), 3871-3882.

Ward, J. (1989). The four-dimensional nature of lotic ecosystems. Journal of the North American Benthological Society, 8(1), 2-8.

Wen-hua, W. (2012). Water Quality Analysis and Composition of Plankton from Lianhuan Lake (Huoshaohei Lake). Journal of Anhui Agricultural Sciences.

White, J., \& Irvine, K. (2003). The use of littoral mesohabitats and their macroinvertebrate assemblages in the ecological assessment of lakes. Aquatic Conservation: Marine and Freshwater Ecosystems, 13(4), 331-351.

Wijesiri, B., Deilami, K., \& Goonetilleke, A. (2018). Evaluating the relationship between temporal changes in land use and resulting water quality. Environmental pollution, 234, 480-486.

Wu, F., Xie, Z., Lan, Y., Dupont, S., Sun, M., Cui, S., . . . Hu, M. (2018). Short-term exposure of Mytilus coruscus to decreased $\mathrm{pH}$ and salinity change impacts immune parameters of their haemocytes. Frontiers in physiology, 9, 166.

Xiao, H., Zang, S., Guan, Y., Liu, S., Gao, Y., Sun, Q., . . . Pei, X. (2014). Assessment of potential risks associated with heavy metal contamination in sediment in Aobaopao Lake, China, determined from sediment cores. Ecotoxicology, 23(4), 527-537.

Yu, G., Harrison, S. P., \& Xue, B. (2001). Lake status records from China: data base documentation: Citeseer.

Yu, S., Xu, Z., Wu, W., \& Zuo, D. (2016). Effect of land use types on stream water quality under seasonal variation and topographic characteristics in the Wei River basin, China. Ecological Indicators, 60, 202-212.

Yu, Z., Wang, H., Miao, M., Kong, Q., Quan, Q., Wang, R., \& Liu, J. (2020). Long-term monitoring of community succession in impoundment lake: Responses of macroinvertebrate to South-to-North Water Diversion Project. Ecological Indicators, 118, 106734.

Zhang, Q., Yang, T., Wan, X., Wang, Y., \& Wang, W. (2021). Community characteristics of benthic macroinvertebrates and identification of environmental driving factors in rivers in semi-arid areas-A case study of Wei River Basin, China. Ecological Indicators, 121, 107153.

Zhijun, G., Ping, X., Huijuan, T., \& Shida, W. (2001). The influence of eutrophycation upon community structure and biodiversity of macrozoobenthos. Shui Sheng Sheng wu Hsueh bao= Acta Hydrobiologica Sinica, 25(3), 210-216.

\section{Hosted file}

Figure\&Table\&Appendix.docx available at https://authorea.com/users/437310/articles/539039influence-of-environmental-variables-on-macroinvertebrate-community-structure-in-

lianhuan-lake 